decasílabos y heptasílabos, y de la VII (Dido a Eneas) en romance de arte mayor, por Eugenio Gerardo Lobo (Madrid, $\left.175^{8}\right)^{\mathbf{1 5}}$;

I 5.-Carta de Enone a Paris (heroida V), traducida en tercetos por el Abate Marchena ${ }^{18}$;

I6.--traducción íntegra, en romances hendecasílabos, por Anastasio de Ochoa (Las Heroidas de Ovidio traducidas por un mexicano. 2 vols., México, I 828);

I 7.- - carta de Ariadna a Teseo (heroida X), traducida en tercetos por el mismo Anastasio de Ochoa (Poesías de un mexicano, Nueva York, I 828, vol. I, págs. I 48-ı 6 I) ;

I 8.-Por último, hay que registrar el monólogo poético Ariadna, de don Manuel José Quintana (Bibl. Aut. Esp., vol. XIX, págs. I I-I2), mitad traducción y mitad imitación de la heroida $\mathrm{X}$.

El Colegio de México.

Antonio Alatorre

\title{
SOBRE LA BIBLIOTECA DEL INCA
}

Nos permitimos añadir algunas apostillas al interesante artículo de José Durand La biblioteca del Inca, en NRFH, II, I 948, págs. 238-264.

42 Puede ser Orationes septem Carolii Sigonii, Venecia, I56o; cf. Renouard, pág. I 80.

8I Podría ser también Chr. Andrichomius, Theatrum Terrae Sanctae (fines del xvi). [De esta obra hubo traducción española, Breve descripción de la ciudad de Jerusalén, Valencia, I 603. Anotamos también: Pedro de Escobar Cabeza de VACA, Lucero de la Tierra Santa, Valladolid, I 587.$]$

io6 Una edición de Marc'Antonio Sabellico, Rerum Venetarum ab urbe condita libri, o la traducción portuguesa, Coronica geral de M. A. Cocio Sabelico, Coimbra, I550; cf. British Museum, Catalogue, voi. XVI, pág. I 5 .

io8 Tal vez Pasquale Caracciolo, La gloria del cavallo, Venecia, I 566, I 585, I 589 .

i 8 Probablemente Francesco Guicaiardini, Dell'Epitome dell'Historia d'Italia, Venecia, I 580.

i 37 Puede ser más bien Alessandro Piccolomini, Della Filosofia $\mathrm{Na}$ turale, Venecia, I554. La primera parte se halla a veces separada de la segunda.

15 Varias poesías, y entre ellas muchas del Excmo. Señor Don Eugenio Gerardo Lobo, theniente general del exercito ... Nueva edición, corregida y aumentada con muchas piezas postumas, en verso y prosa, y otras ineditas de diversos autores. 2 vols. Las traducciones de Ovidio están en el voi. II, págs. 150-183.

${ }_{16}$ Véase en sus Obras literarias, ed. de Menéndez y Pelayo, tomo I, Sevilla, I892, págs. $73-80$. 
I 42 Podría ser Federico Grisone, Ordini del cavalcare et modi di conoscere le nature de cavalli, primera edición en Nápoles, I $55^{\circ}$ (o una de las muchas reimpresiones de la segunda mitad del siglo xvi). [Hubo traducción española de Antonio Flores de Benavides, Baeza, I568: Reglas de la caballería y de la brida y para conocer la complexión y naturaleza de los caballos.]

I 46 No debe excluirse la posibilidad de que sea Paris de Puteo, Duello: libro de re, imperatori, etc., muy en boga durante el xvI, obra de la cual Palau cita una traducción española.

I $4^{8}$ De çinco lenguas. Podría tratarse del Psalterium poliglota (hebreo, caldeo, griego, árabe y latín) impreso en Génova, I 5 I6, célebre por la noticia biográfica de Cristóbal Colón que contiene (cf. Harrisse, págs. I 54 y sig.). Si es un diccionario en cinco lenguas, será el de NoËl de Barlaimont, Dictionariolum 5 linguarum (Amberes, I 545, con reediciones), o François Garon, Quinque linguarum utilissimus vocabulista (Nuremberga, I $53 \mathrm{I}$, con dos reimpresiones) ; menos probables son otros pequeños vocabularios que recuerda Craarles Beaulieux, Liste des Dictionnaires, en Mélanges Brunot, Paris, I 904.

I 54 De la teorica. Podría ser Alessandro Piccolomini, La prima parte de le Theoriche o vero speculationi dei pianeti, de la cual RICCARDI, Biblioteca matematica italiana, II, cols. 272-273, cita tres ediciones de la segunda mitad del xvi. [Piccolomini fué muy leído y estimado por Garcilaso.]

I75 Seraffino. Si se tratase de una biblioteca italiana, diríamos sin duda que se trata de una de las Opere (o Strambotti) del poeta cuatrocentista Serafino Aquilano (Serafino Cimminelli); pero en España creemos se trate más bien de Las obras de don SERAFino DE FERMo, que tratan de la vida espiritual ... traduzidas de la lengua italiana en romance castellano, Medina del Campo, I 554; cf. British Museum, Catalogue, LXII, pág. I9I). [Cf. Durand, loc. cit., pág. 26o.]

I8o Podría ser asimismo Andrea Fulvio, L'antichità di Roma, Roma, I 588, o también una de las cuatro ediciones de BERNARdo GAMUCCI, La antichità della città di Roma, primera edición en I 565. Bajo este título Antigüedades de Roma puede esconderse cualquiera de ellas, pero también podría tratarse de otra obra.

I 87 Treatro del mundo. Anotamos también el Theatrum Orbis Terrarum de Abramo Ortelio, cuya primera edición se publicó en I 570; Palau cita dos traducciones castellanas de esta obra, Amberes, I 588 y I6o2. [La primera de éstas, titulada Teatro de la tierra universal; la segunda, Teatro del orbe de la tierra.]

Firenze.

Bruno Migliorini y Giulio Cesare Olschki 
Agradezco vivamente las eruditas adiciones de los señores Migliorini y Olschki a La biblioteca del Inca, que, como todo trabajo bibliográfico, siempre queda abierto a dudas y rectificaciones. Digámoslo con palabras del mismo Inca: "el árbol queda plantado y el jardín abierto, donde podrá entrar quien quisiere y sacar la rama que más gusto le diere y ponerla en su lugar, con estotras: que a mí se me hará mucha merced en ello". Algunas anotaciones hemos añadido por nuestra parte, entre corchetes. Otras más agregamos a continuación:

Pág. 242, n. I 2: No sólo es "muy probable que su hijo -Diego de Vargas - o Sevillano le sirviesen de pendolistas" a Garcilaso. Refiriéndose a Diego dice un contemporáneo suyo, Íñigo de Córdova Ponce de León: "murió de más de 70 años y juzgo que fué en el de 1652 ; cuan do moço trató de la valentía, después le bí recogido y compuesto; dijome muchas veces q. él había escrito ['copiado'] los Goments. Rs. q. son los libros q. su padre Garcilaso abía escrito de las Indias y q. él [Diego] los

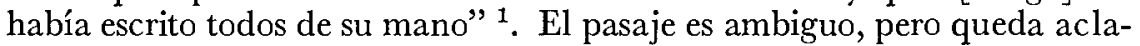
rado si recordamos que en su vejez Garcilaso no podía escribir "por temblalle la mano".

I 5 Para mayor información sobre los diversos Índices, cf. H. Reuscir, Die Indices librorum prohibitorum des xvi Jahrhunderts, Tübingen, I 886.

I 8 Catalogus haereticorum; la $4^{\mathrm{a}}$ y la $5^{\mathrm{a}}$ edición son de Colonia, I 529 y I 537; cf. Clara Louisa Penney, List of books printed before I601, New York, 1929, pág. I31. Dato proporcionado por el Sr. Luis Jaime Cisneros.

40 Flores de la blibia (y núm. 28, Flores blibiorun). En Irving A. LeONARD, The Mexican book-trade, 1576, HR, XVII, I949, pág. 28, aparece un Flores Blibia ynpresso en Leon, tampoco identificado.

$5^{6}$ Vida de santos. Aunque es el título sumamente impreciso - tanto podría ser un Flos Sanctorum de los muchos que corrían, como una obra de título semejante al del inventario-, por su mucha difusión nos inclinamos a creer que se trata de Juan MaldoNADO, Vitae Sanctorum brevi elegantique stylo compositae, Burgos, I 53 I, con reimpresiones. Podría ser también LoRenzo SuRIo, Vitae Sanctorum, Colonia, I 570, o Juan Basilio Sanctoro, La Hagiographía. Vida de los Sanctos de El Nuevo Testamento, Bilbao, I 580 .

64 Libro de Quicoltura. De ser Libro de agricultura sería sin duda, como indicamos, el de Gabriel Alonso de Herrera, impreso más de diez veces durante el siglo xvi; pero es muy probable que Quicoltura deba leerse Auicoltura. Indicación del Dr. Amado Alonso.

1 Cf. Ruben Vargas Ugarte S. J., Nota sobre Garcilaso, en MP, enero-febrero de 1930, núm. 137-138, pág. Io6. 
I 35 Adbertimiento çiviles. Anotamos como posible Marcos Burgos o Didacus Salon de Pace, Prima Pars Quaestionum Civilium, Medina del Campo, I 576; cf. la reseña de L. J. Cisneros en $M d S$, núm. 3, marzo-abril de i949, pág. 84.

Pág. 262: Otro de sus amigos, el jesuíta Jerónimo de Prado $^{2}$, fué autor, en colaboración con J. B. Villalpando, de las In Etzechielem explanationes et apparatus novis ac templi Hierosolymitani, Roma, I 569I604, 3 vols.

Ibid.: Como señala Miró Quesada (El Inca Garcilaso, pág. 238), el Inca utilizó las Cartas anuas de los jesuítas. Escribe el Inca: “ . . como consta por las relaciones que los Padres de la Sancta Compañía de Jesús embiaron a su Generalíssimo de los sucessos notables del Perú, del año de mil y seiscientos y dos . . . los cuales me dió el Padre Maestro Francisco de Castro, natural de Granada, que este año de seiscientos y cuatro es perfecto de las escuelas deste sancto colegio de Córdova" (Comentarios, lib. VII, cap. xxv). Ahora bien, según Clara Louisa Penney (List of books printed, I6oI-170o, New York, I938, pág. 322), las Annuae litterae Societatis Iesu correspondientes a 1602 no se imprimieron hasta I6 18 , fecha posterior a la muerte del Inca. Parece, pues, que las debió conocer manuscritas, o quizás sólo leyó los pasajes de que trata, facilitados por el padre Castro.

Pág. 263: Libro que no aparece en el inventario y que tampoco menciona el Inca en su obra, pero que sabemos leyó muy cuidadosamente, son los Tratados del padre Las Casas, Sevilla, I 552-I 553. Vargas Ugarte, hace ya bastantes años, examinó un ejemplar que perteneció al Inca y luego pasó a poder de su amigo don Diego de Córdova ${ }^{3}$. Anota éste en una guarda: "de hordinario decía [Garcilaso] q. no le lucía su hacda. por haberse traydo de las Indias y abérsele quitado a aquellas jentes contra derecho y a este propósito citaba este libro". Referencias personales a Las Casas, no a sus escritos, hay en la Historia general, lib. III, caps. xIx y sigs.; lib. IV, caps. I y sigs. En cambio, Blas Valera (apud Comentarios reales, lib. II, cap. vI) menciona los escritos de fray Bartolomé.

Ibid.: En los Comentarios hallamos algo que puede tenerse como una alusión a don Juan Manuel. Los nombres Cápac y Yupanqui, escribe Garcilaso, "también los han tomado muchos de la sangre real, haziendo sobrenombre el nombre proprio que a los Incas dieron, como han hecho

2 Cf. Diálogos de amor, dedicatoria a Maximiliano de Austria de 1586 ; Ciomentarios reales, lib. II, cap. vn.

${ }^{3}$ Cf. loc. cit. Las anotaciones de Diego de Córdova y de Iñigo de Córdova Ponce de León al ejemplar de los Tratados son de mucho interés; como la Nota de Vargas Ugarte se publicó en i930 y la Nueva documentación de José DE LA ToRRE Y DEL CERRO no apareció hasta 1935, se ha descuidado la confrontación de ambas. Escribe Iñigo de Córdova: "murió en un ospital por su boluntad quidando los pobres en q. asistió muchos días". A la luz de los documentos de Torre y del Cerro, este hospital se identifica con el de la Limpia Concepción, llamado también de Antón Cabrera, que hasta hoy subsiste. Allí vivió el Inca cuando fué mayordomo del mismo hospital, y allí, según los datos que aparecen en este viejo ejemplar de Las Casas, fué donde falleció en 1616 , por los mismos días en que murieron Cervantes y Shakespeare, y quizás el mismo día que Cervantes, 23 de abril. 
en España los del apellido Manuel, que, haviendo sido nombre proprio de un Infante de Castilla, se ha hecho sobrenombre en sus descendientes" ". Como se sabe, el infante don Manuel, hijo de Fernando el Santo, fué padre del célebre escritor, a partir del cual el nombre de pila de su padre empieza a usarse como apellido.

Corregimos algunos errores; pág. 249, núm. 59: Córdoba debe ser Amberes; pág. 250, núm. 65: Toledo, I59o corresponde a Pérez de Guzmán y Medina del Campo, $155 I$ a Juan Sedeño; pág. 25I, núm. 75: Cosmografía debe ser Cronografía; pág. 263 , nota 27: cap. xxiv debe ser cap. xxiii.

El Colegio de México.

José Durand

${ }^{4}$ Lib. II, cap. xvIn. 